\title{
A first experience with Problem-based learning in a course of Psychometrics
}

\section{Laura Galiana}

Department of Methodology for the Behavioral Sciences, University of Valencia, Spain.

\begin{abstract}
The aim of this study was to describe students' perceptions on problem-based learning $(P B L)$ when applied in a course of Psychometrics. 34 students participated in the course. Activities were conducted in groups of three students during two sessions of two hours each, and included the traditional steps in the PBL tutorial process. Participants were surveyed on their perceptions on $P B L$, acquisition of competences in $P B L$ vs Traditional learning, and will to use PBL methodology in the future. Results pointed that students' perceived PBL could help them to improve group work and problem resolution. Students preferred PBL methodology to acquire responsibility for learning, work with groups and conflicts, acquire a receptive attitude, and skills related to share information and learn from others. Finally, around $60 \%$ of the students expressed their will to take more courses (either Psycometrics or other courses) using PBL. These findings are a starting point to use the PBL methodology in other contexts different to the medical education. Specifically for Psychometrics teachers, it is of importance to rely in a methodology that provides students satisfaction, will to repeat, while acquiring the contents of the cours and general competences.
\end{abstract}

Keywords: Problem-based learning (PBL); Psychometrics; Problem-solving; Group work. 


\section{Introduction}

Problem-based learning (PBL) is increasingly used in multiple disciplines, with its origins in medical education (Savery, 2015). This educational method is fundamentally a studentcentered approach to learning, in which teachers present problems or scenarios to the students. These problems may provide a context to tap the learning objectives, which either can be course level objectives, or more specific ones (Barrows, 1985; Barrows \& Kelson, 1995).

Although there are 'many species and subspecies' of PBL (Barrows, 1986), that is to say, it can be implemented in several ways, most of them share some fundamental characteristics: it is an educational approach whereby the problem is the startingpoint of the learning process; it is a participant-directed learning processes, or 'self-directed learning', which has a far more individual-oriented focus; PBL is a experience learning, where the student builds from his/her own experiences and interests; it is an activity-based learning, requiring activities involving research, decision-making and writing; the solution of the problem can extend beyond traditional subject-related boundaries and methods; and it is a group-based learning, as the majority of the learning process takes place in groups or teams (Barrows, 1996; Kolmos, 1999; van der Vleuten, Norman \& de Graaff, 1991).

Among the positive characteristics of PBL, there is the promotion of a positive attitude towards learning, the active and intensive students' participation, the students' search of information to support their hypotheses, and the collaboration between students (Gilbert, 1997). Indeed, authors have pointed several advantages of PBL when compared to traditional, teacher-focused educational methodologies, including activation of prior knowledge, elaboration on newly acquired knowledge, contextual learning, and general problem-solving skills (Dolmans \& Schmidt, 1996); improvement of cognitive skills: critical thinking, analysis, synthesis and evaluation, learning concepts and contents of the subject of study with a positive attitude, ability to identify, analyze and solve problems, ability to detect learning needs, manage efficiently different sources of information, understand phenomena of the specific and contextual environment, listen and communicate effectively; participate in the decision-making process, demonstrate security and autonomy in actions, and questioning the proper scale of values: honesty, responsibility and commitment (Mendoza \& Bernabeu, 2006). Specifically in the medical education arena, PBL has been found to enhance self-directed learning skills (Norman \& Schmidt, 1992), stimulate students to become self-directed learners (Blumberg \& Michael, 1992; Schmidt \& van der Molen, 2001), improve students satisfaction (Albanese \& Mitchell, 1993; Berkson, 1993; Vernon \& Blake, 1993), and improve knowledge and clinical performance (Colliver, 2000). 
Although there is plenty of evidence of PBL advantages for medical education, empirical evidence in other fields, such as Psychology, is scarce. This is specially true when it comes to those "less clinical" courses of Psychology, such as Statistics or Psychometrics. Indeed, no studies of PBL applications during a course on Psychometrics have been published, as far as we know.

Taking into account this literature review, the aim of this study was to describe students' perceptions on PBL in a course of Psychometrics, gathering both information on which competences are acquired with PBL and also comparing the acquisition of skills in PBL and traditional leraning.

\section{Methods}

\subsection{Design, setting, and procedure}

This research was carried out during the introductory course to Psychometrics that Psychology students take during the second year of the Psychology Degree. It is an annual course, of 9 ECTS. The PBL activity was implemented to cover the learning objective of evidence of content validity, which is the first content in the second semester. The specific objectives included were: description of content validity, areas of content validity, methods of estimation of content validity, and main guidelines to guarantee test content validity. The scenario presented to the students was adapted from Santiesteban (2009), as follows:

"A Psychometrics student is studying for the exam. She puts a lot of effort and dedicates a lot of time to study, because the concepts are interesting for her. Also, she considers them basic to understand many others areas of Psychology.

Therefore, the student is very interested in obtaining a good mark in the final exam. She is reasonably confident, because although there are topics that she knows better than others, she considers that she has a good general level of knowledge.

After the exam, she is not satisfied with the result: she has failed. Why? She asks. Her personal conditions were excellent to perform on that test. What happened? 'Nothing strange', she says to a classmate, 'I just failed because of the 7 topics on the agenda, they asked me the only one I didn't knew.'

The exam, whose aim was to evaluate the knowledge acquired in the introductory course of Psychometrics, focused only on one of the contents of the program. Was it a good test? Did it correctly measure the basic knowledge of Psychometrics? Were the exam contents biased? How can we make sure we have a good exam?”

The different activities were conducted in groups of three students during two sessions of two hours each. Activities included the traditional steps in the PBL tutorial process: (1) 
identify and clarify unfamiliar terms presented in the scenario; (2) define the problem to be discussed; (3) "brainstorming” to discuss the problem, suggesting hypothetical explanations based on prior knowledge; identify areas of incomplete knowledge; th one member of the group records all the discussion; (4) review steps 2 and 3 and arrange explanations into tentative solutions; one member of the group organises the explanations and restructures if necessary; (5) formulate learning objectives; tutor ensures learning objectives are achievable, comprehensive, and appropriate; (6) private study and information gather to each learning objective; and (7) group shares results of private study; tutor checks learning; assessment (Wood, 2003).

After the two sessions, an online survey was conducted using SurveyMonkey®. It took approximately five minuts of duration, and participation was informed and consent.

\subsection{Participants}

34 students participated in the session and completed the survey. Most of them $(N=31$; 91.2\%) were women. Age ranged from 19 to 21 years old. Information on students' achievement on the first semester of the Psychometrics course can be consulted in Table 1 .

Table 1. Marks on the first semester of the course of Psychometrics.

\begin{tabular}{ccccc}
\hline Variable & Mean & $\begin{array}{c}\text { Standard } \\
\text { Deviation }\end{array}$ & $\begin{array}{c}\text { Minimum } \\
\text { score }\end{array}$ & $\begin{array}{c}\text { Maximum } \\
\text { score }\end{array}$ \\
\hline Activities & 15.73 & 1.33 & 12.00 & 17.00 \\
Exam mark & 7.69 & 1.61 & 3.13 & 10.00
\end{tabular}

Source: Own elaboration. Notes: Students were required 17 activities during the first semester (values ranged from 0 to 17); exam mark could range from 0 to 10 , being 5 the minimum score required to pass the exam.

\subsection{Variables}

Participants were surveyed on several questions, based on previous literature regarding PBL:

- Perceptions on PBL. Students had to score, in a five-point Likert-type scale, to what extent they thought the PBL could help them to acquire the following competences: problem resolution, decision making, group work, planification of learning strategies, critical thinking, assessment and self-assessment skills, and permanent learning.

- $\quad P B L$ vs Traditional learning. Students were asked to compare the PBL experience with the traditional classes, "in which the teacher explains the contents". They had to chose which methodology was more helpful to acquire a list of competences, 
the traditional learning, the PBL, or both equally. The competence list included: take responsibility for learning; work with different groups managing possible conflicts that arise; have a receptive attitude towards the exchange of ideas with colleagues; share information and learn from others; be autonomous in learning (find information, contrast it, understand it, apply it, etc.) and know how to ask for help and guidance when you need it; and have the necessary strategies to plan, control and evaluate the steps you take in your learning

- Will to use PBL methodology in the future, either in Psychometrics courses or other subjects.

\subsection{Data analyses}

Statistical analyses included descriptive statistics. In order to describe the students' perceptions on PBL, mean, standard deviations, and minimum and maximu scores were calculated. For the purpose of comparing traditional learning and PBL, and also to study the will to use PBL methodology in the future, frequencies and percentages were calculated.

\section{Results}

As reported in Table 2, students' perceived PBL could help them to improve group work and problem resolution quite well, with a mean of almost four points in a five-point scale. The rest of the skills obtained scores in the middle of the scale, around three.

As regards the comparison between PBL and traditional learning, more than two thirds of the students preferred PBL methodology to acquire responsibility for learning, work with groups and conflicts, and acquire a receptive attitude. PBL was also preferred for half the students to work skills related to share information and learn from others, whereas only $5.9 \%$ pointed traditional learning for this purpose. Finally, similar results were obtained for traditional leraning and PBL when the skills to acquire were related to autonomous learning and planning and control strategies. More details can be consulted in Table 3.

Finally, regarding the implementation of the PBL methodology in the Psychometrics course and in other subjects, around $60 \%$ of the students expressed their will to take more courses (either Psycometrics or other courses) using PBL, as it is shown in Table 4. 
Table 2. Students' perceptions of PBL.

\begin{tabular}{ccccc}
\hline Variable & Mean & $\begin{array}{c}\text { Standard } \\
\text { Deviation }\end{array}$ & $\begin{array}{c}\text { Minimum } \\
\text { score }\end{array}$ & $\begin{array}{c}\text { Maximum } \\
\text { score }\end{array}$ \\
\hline Problem resolution & 3.84 & 0.87 & 2.00 & 5.00 \\
Decision making & 3.38 & 0.92 & 1.00 & 5.00 \\
Group work & 3.93 & 1.02 & 2.00 & 5.00 \\
Planification of learning strategies & 3.17 & 0.93 & 1.00 & 5.00 \\
Critical thinking & 3.23 & 1.28 & 1.00 & 5.00 \\
Assessment and self-assessment skills & 3.08 & 1.16 & 1.00 & 5.00 \\
Permanent learning & 2.88 & 1.17 & 1.00 & 5.00 \\
\hline
\end{tabular}

Source: Own elaboration.

Table 3. Comparison of PBL and traditional learning.

\begin{tabular}{cccccccc}
\hline Variable & $\begin{array}{c}\text { Prefered traditional } \\
\text { learning }\end{array}$ & Both equally & \multicolumn{2}{c}{ Prefered PBL } \\
& $\mathbf{N}$ & $\mathbf{\%}$ & $\mathbf{N}$ & $\mathbf{\%}$ & $\mathbf{~ N}$ & $\mathbf{\%}$ \\
\hline Take responsibility for learning & 7 & 20.6 & 4 & 11.8 & 23 & 67.6 \\
Work with groups and conflicts & 3 & 8.8 & 7 & 20.6 & 23 & 67.6 \\
Receptive attitude & 2 & 5.9 & 9 & 26.5 & 23 & 67.6 \\
Share information and learning & 4 & 11.8 & 12 & 35.3 & 18 & 52.9 \\
Autonomous learning & 11 & 32.4 & 11 & 32.4 & 12 & 35.3 \\
Planning and control strategies & 11 & 32.4 & 11 & 32.4 & 12 & 35.3 \\
\hline
\end{tabular}


Table 4. Will to take more courses with PBL methodology.

\begin{tabular}{|c|c|c|c|c|c|c|}
\hline \multirow[t]{2}{*}{ Variable } & \multicolumn{2}{|c|}{ No } & \multicolumn{2}{|c|}{ Don't mind } & \multicolumn{2}{|c|}{ Yes } \\
\hline & $\mathbf{N}$ & $\%$ & $\mathbf{N}$ & $\%$ & $\mathbf{N}$ & $\%$ \\
\hline $\begin{array}{l}\text { Will you like to use PBL again in the Psychometrics } \\
\text { course? }\end{array}$ & 6 & 17.6 & 6 & 17.6 & 22 & 64.7 \\
\hline $\begin{array}{l}\text { Will you like to use PBL again in different courses of } \\
\text { the degree (Personality, Learning Difficulties...)? }\end{array}$ & 7 & 20.6 & 7 & 20.6 & 20 & 58.8 \\
\hline
\end{tabular}

Source: Own elaboration.

\section{Discussion and conclusion}

Although problem-based learning (PBL) is a relatively old educational methodology, most of the studies published had focused on its implementation in medical education. Research on the arena of Psychology is quite limited, and no results on courses related to Statistics or Psychometrics have been found. Because of that, the aim of the current study was to analyze students' perceptions of PBL when applied in a course of Psychometrics.

Results showed that PBL promoted, as perceived by the students, general problem-solving and group work skills, as already pointed by Dolmans and Schmidt (1996) and Mendoza and Bernabeu (2006). However, our evidence did not supported the previous findings that related PBL to better planification of learning strategies, critical thinking, or autonomous learning (Blumberg \& Michael, 1992; Norman \& Schmidt, 1992; Schmidt \& van der Molen, 2001). In fact, when students were asked to compare PBL to traditional learning methodologies, autonomous learning and planning and control strategies were perceived as skills equally acquired with both methodologies, with almost the same amount of students chosing one or other learning methodology. The last PBL issue assessed was willingness to repeat, with more than half of the students expressing their wish to work with this methodology again in the future, either in Psychometrics or in other course of the Degree of Psychology. This could be attributed to the skills acquired, but also could be understood as satisfaction with the methodology, as pointed in previous research in the medical context (Albanese and Mitchell, 1993; Berkson, 1993; Vernon \& Blake, 1993).

Although the research has several limitations, including the small sample size and its descriptive nature, the findings are rewarding. Results are a starting point to use the PBL methodology in other contexts, different to the medical and clinical situations we are used to. Specifically for Psychometrics teachers, a mandatory course in the degree of Psychology that is many times approached with disinterst, it is of importance to rely on a methodology that provides students satisfaction, will to repeat, while acquiring the contents of the cours 
and general competences. Future research using bigger, more representative samples and studying the relation between the use of the PBL methodology and students' outcomes would be welcomed.

\section{References}

Albanese, M. A., \& Mitchell, S. (1993). Problem-based learning: areview of literature on its outcomes and implementa-tion issues. Academic Medicine, 68, 52-81.

Barrows, H. S. (1986). A taxonomy of problem-based learning methods. Medical Education, 20, 481-486.

Barrows, H. S. (1996). Problem-based learning in medicine and beyond: A brief overview. In W. H. Gijselaers (Ed.), New directions for teaching and learning (pp. 3-11). San Francisco: Jossey-Bass.

Barrows, H., \& Kelson, A. C. (1995). Problem-Based Learning in Secondary Education and the Problem-Based Learning Institute (Monograph 1). Springfield, IL: ProblemBased Learning Institute.

Berkson, L. (1993). Problem-based learning: have the expecta-tions been met? Academic Medicine, 68, S79-S88.

Blumberg, P., \& Michael, J. A. (1992). Development of self-directedlearning behaviours in a partially teacher-directedproblem-based learning curriculum. Teaching and Learning in Medicine, 4(1), 3-8.

Colliver, J. A. (2000). Effectiveness of problem-based learningcurricula: research and theory. Academic Medicine, 75(3), 259-266.

Dolmans, D., \& Schmidt, H. (1996). The advantages of problem-based curricula. Postgrad Medical Journal, 72, 535-538.

Gilbert, C. M. (1997). Guía pedagógica para los profesionales de la salud de la OMS. Valladolid: Universidad de Valladolid.

Kolmos, A. (1999). Progression of collaborative skills. In J. Conway and A. Williams (Eds.), Themes and Variations in PBL (pp. 129-138). Callaghan, NSW: Australian Problem Based Learning Network.

Mendoza, X., \& Bernabeu, M. D. (2006). Aprendizaje basado en problemas. Competencias del profesional de la salud. Innovación Educativa, 6, 1-12.

Norman, G. R., \& Schmidt, H. G. (1992). The psychological basis of PBL. A review of the evidence. Academic Medicine, 67(9), 557-565.

Savery, J. R. (2015). Overview of problem-based learning: definitions and distinctions. In C. E. Hmelo-Silver and P. A. Ertmer (Eds.), Essential readings in problem-based learning (pp. 5-16). USA: Authors.

Schmidt, H. G, \& van der Molen, H. T. (2001). Self-reported com-petency ratings of graduates of a problem-based curriculum. Academic Medicine,76(5), 466-468.

van der Vleuten, C. P. M., Norman, G. R., \& de Graaff, E. (1991). Pit-falls in the pursuit of objectivity: Issues of reliability. Medical Education, 25, 110-118. 
Vernon, D. T. A., \& Blake, R. L. (1993). Does problem-based learningwork? A metaanalysis of evaluative research. Academic Medicine, 68, 550-563

Wood, D. F. (2003). ABC of learning and teaching in medicine. Problem based learning. BMJ, 326, 328-330. 